\title{
Intussusceptions due to trauma in a 17-month-old infant
}

\author{
Haleh Mousavi ${ }^{1}$, Samad Shams Vahdati2 ${ }^{*}$, Roshan Fahimi ${ }^{2}$ \\ 'Emergency Department, Tabriz University of Medical Sciences, Tabriz, Iran \\ ${ }^{2}$ Road Traffic Injury Research Center, Tabriz University of Medical Sciences, Tabriz, Iran
}

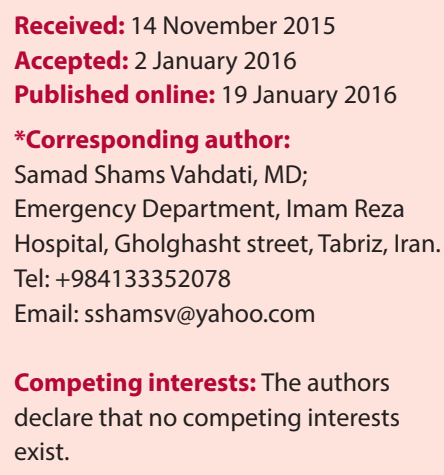

\begin{abstract}
Invagination is a kind of intestine disease in children and it is occurred between 2 upto 14 years old. This is a report of 17 months infant with intussusception due to trauma. The patient had admitted to emergency department because of motor vehicle accident and because of abdominal pain, abdominal computed tomography (CT) scan was done. Keywords: Intussusception, Trauma, Infant

Citation: Mousavi H, Shams Vahdati S, Fahimi R. Intussusceptions due to trauma in a 17-month-old infant. Journal of Emergency Practice and Trauma 2017; 3(2): 66-67. doi: 10.15171/jept.2015.14.
\end{abstract}

\section{Introduction}

Invagination or intussusception is defined as the telescoping of one segment of the intestine into the lumen of an immediately adjacent part, causing partial or complete intestinal obstruction. It is common between the ages of 2 and 14 years old. Five percent of the cases are found in adults. Traumatic abdominal pain, as a chief complaint, includes 5\%-10\% of visits in emergency departments (1-3). The following case is of interest because trauma initiated an attack of intussusceptions.

\section{Case Presentation}

A 17-month-old infant was admitted to our hospital after a motor vehicle accident. In the assessment of the patient according to Advanced Trauma Life Support guideline, only abdominal pain was observed by touch. No free fluid was detected in focused assessment with sonography in trauma (FAST). Due to the age of the patient, a double contrast computed tomography (CT) of abdomen and pelvic was requested (Figure 1).

\section{Discussion}

Barbette was the first person who described intussusceptions in 1674 (4). The exact mechanism of invagination is still unknown; however it is believed that it may be caused by the growth of any lesions in the intestine or by other specific conditions that cause the intestine to contract strongly. It can also be caused by trauma. It becomes obvious when an infant suddenly experiences paroxysmal abdominal pain with vomiting and restlessness $(5,6)$. Imaging has become particularly helpful in supporting the clinical diagnosis and it also plays an important role in clinical management decisions made by clinicians. ultrasonography examination of abdomen has a growing designation in the diagnosis of different causes of abdominal pain accurately. The protocol which is used in acute traumatic abdominal pain is FAST. Based on FAST examination, intra-abdominal pathologies such as intussusceptions can be detected. US examination has a sensitivity of $98 \%-99 \%$ and specificity of $88 \%-89 \%$ in diagnosing intussusception. CT scan has been found particularly to give reliable information, but its role is still a controversial issue. $(3,7-10)$

In 1948 another case of trauma-induced invagination was reported by James Cook. The case report was about a 17 year old boy who received a severe blow in the right lower abdomen complaining of central abdominal pain. On physical examination, general abdominal tenderness and muscle guarding were noted and a tender mobile mass was palpable to the right of umbilicus. During surgery, it became apparent that the condition was an ileocolic intussusception. Reduction was necessary to resect $83 \mathrm{~cm}$ of gangrenous terminal ileum. Operation was completed by the formation of a double-barrel ileostomy.

Recently abdominal CT scan has been reported to be the most useful imaging technique. Therefore, we suggest that all patients presenting with suspected invagination should have an abdominal CT scan as a regular diagnostic test. Intraoperative colonoscopy might be helpful for investigating malignant and benign lesions before reduction of intussusceptions. We think that pathologic diagnosis like recto sigmoid intussusceptions which locate in the mu- 

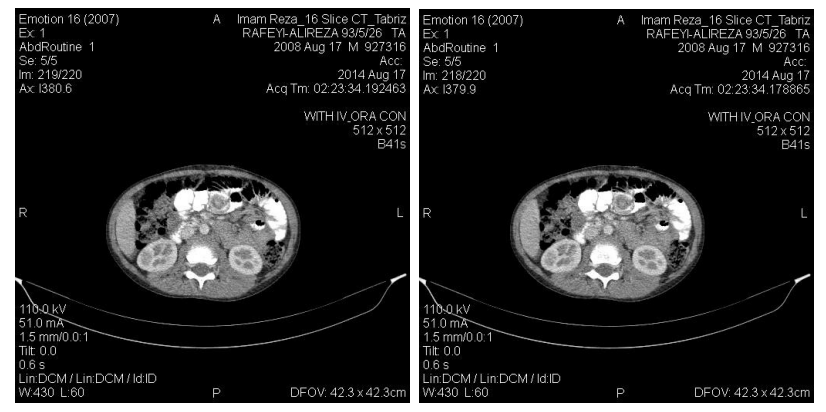

Figure 1. Double contrast abdominal CT scan.

cosa could made by colonoscopy (11-13). The invasive double contrast imaging which was requested in our case report underwent intubation using a special catheter with a double lumen and balloon to the proximal jejunum and was performed under CT imaging. However; diagnosis is usually made during surgery (10). Diagnostic Laparoscopy can be used in the diagnosis of those cases of invagination which are suspected but not confirmed by preoperative work-up. Diagnosis using MRI is not a routine choice either in children or adults (14).

\section{Ethical issues}

The authors have obtained permission before using patient data and images.

\section{Authors' contributions}

HM: Case management; SSV: Planing and critique; RF: Writing and editing.

\section{References}

1. Bines JE, Kohl KS, Forster J, Zanardi LR, Davis RL, Hansen $\mathrm{J}$, et al. Acute intussusception in infants and children as an adverse event following immunization: case definition and guidelines of data collection, analysis, and presentation. Vaccine 2004; 22(5-6): 569-74.

2. Bines JE, Patel M, Parashar U. Assessment of postlicensure safety of rotavirus vaccines, with emphasis on intussusception. J Infect Dis 2009; 200 Suppl 1: S282-90. doi: $10.1086 / 605051$.

3. Walsh PF, Crawford D, Crossling FT, Sutherland GR, Negrette JJ, Shand J. The value of immediate ultrasound in acute abdominal conditions: a critical appraisal. Clin Radiol 1990; 42(1): 47-9.

4. Nonose R, Valenciano JS, da Silva CM, de Souza CA, Martinez CA. Ileal intussusception caused by Vanek's tumor: a case report. Case Rep Gastroenterol 2011; 5(1): 110-116. doi: 10.1159/000326930.

5. Murphy TV, Gargiullo PM, Massoudi MS, Nelson DB, Jumaan AO, et al. Intussusception among infants given an oral rotavirus vaccine. N Engl J Med 2001; 344(8): 564-72. doi: 10.1056/NEJM200102223440804.

6. Patel MM, Haber P, Baggs J, Zuber P, Bines JE, Parashar UD. Intussusception and rotavirus vaccination: a review of the available evidence. Expert Rev Vaccines 2009; 8(11): 155564. doi: 10.1586/erv.09.106.

7. Allemann F, Cassina P, Rothlin M, Largiader F. Ultrasound scans done by surgeons for patients with acute abdominal pain: a prospective study. Eur J Surg 1999; 165(10): 966-70. doi: 10.1080/110241599750008099.

8. Rosen MP, Siewert B, Sands DZ, Bromberg R, Edlow J, Raptopoulos V. Value of abdominal CT in the emergency department for patients with abdominal pain. Eur Radiol 2003; 13(2): 418-24. doi: 10.1007/s00330-002-1715-5.

9. Erkan N, Haciyanli M, Yildirim M, Sayhan H, Vardar E, Polat AF. Intussusception in adults: an unusual and challenging condition for surgeons. Int J Colorectal Dis 2005; 20(5): 452-6. doi: 10.1007/s00384-004-0713-2.

10. Bays D, Anagnostopoulos GK, Katsaounos E, Filis P, Missas S. Inflammatory fibroid polyp of the small intestine causing intussusception: a report of two cases. Dig Dis Sci 2004; 49(10): 1677-80.

11. Esses D, Birnbaum A, Bijur P, Shah S, Gleyzer A, Gallagher EJ. Ability of CT to alter decision making in elderly patients with acute abdominal pain. Am J Emerg Med 2004; 22(4): 270-2.

12. Barussaud M, Regenet N, Briennon X, de Kerviler B, Pessaux P, Kohneh-Sharhi N, et al. Clinical spectrum and surgical approach of adult intussusceptions: a multicentric study. Int J Colorectal Dis 2006; 21(8): 834-9. doi: 10.1007/ s00384-005-0789-3.

13. Tan KY, Tan SM, Tan AG, Chen CY, Chng HC, Hoe MN. Adult intussusception: experience in Singapore. ANZ J Surg 2003; 73(12): 1044-7.

14. Sampson MA, Lyons TJ, Nottingham J, Naik D. Ultrasound diagnosis of recurrent intussusception due to inflammatory fibroid polyp of the ileum. J Ultrasound Med 1990; 9(7): 423-5. 